\title{
Inhaler Technique Training and Health-Care Professionals: Effective Long-Term Solution for a Current Problem
}

\author{
Iman A Basheti PhD, Eyad A Qunaibi PhD, Salim A Hamadi PhD, \\ and Helen K Reddel PhD
}

\begin{abstract}
INTRODUCTION: The aims of this study were (1) to assess the ability of a range of health-care professionals (HCPs: specialists [physicians specializing in management of airways disease], general practitioners, pharmacists, pharmacist assistants, nurses, and respiratory therapists) in Jordan to demonstrate the correct use of some commonly used inhalers using standardized checklists, with highest scores indicating optimal use, and (2) to evaluate the short-term and long-term effectiveness of a single educational intervention on the HCPs' skills in using inhalers. METHODS: HCPs' inhaler technique was assessed at baseline. All HCPs were then invited to attend a workshop on asthma management with particular reference to inhaler use. At the workshop, HCP skills in inhaler technique were optimized. Inhaler technique was assessed before and after training. All participants were assessed on their inhaler technique at follow-up (after 4 months). RESULTS: Two hundred HCPs (10 specialists, 46 general practitioners, 79 pharmacists, 15 pharmacist assistants, 40 nurses, and 10 respiratory therapists) participated in the study. Specialists scored highest on baseline inhaler technique demonstration skills. All HCPs scored poorly in demonstrating the correct use of the dry powder inhalers when compared with pressurized metered-dose inhalers (MDIs) (range of mean scores \pm SD: MDI, $7.24 \pm 0.97$ to $8.70 \pm 0.67$; Diskus, $4.83 \pm 0.51$ to $6.30 \pm 1.7$; Turbuhaler, $4.90 \pm 0.32$ to $6.40 \pm 1.7$ ). Participants attending the workshop showed improved inhaler skills (mean scores before and after training: MDI, $4.77 \pm 1.60$ vs $8.77 \pm 0.52$; Diskus, $4.40 \pm 2.60$ vs $8.85 \pm 0.41$; Turbuhaler, $4.96 \pm 2.05$ vs $8.63 \pm 0.67)$. Four months after the workshop, the inhaler technique of 129 participants was again assessed. Those who had attended the workshop $(n=48)$ scored significantly higher mean scores for all devices (score $=7.64$ ) than nonattendees $(n=81$, score $=5.99, P<.001)$, by one-way analysis of covariance. CONCLUSIONS: With the exception of specialists, HCPs in Jordan need to be updated on their inhaler technique skills, specifically the newer dry powder inhalers. A single effective educational workshop on inhaler technique can significantly improve HCPs' long-term ability to demonstrate these skills. Key words: health-care professionals; inhaler technique; education; asthma; train the trainer; Jordan. [Respir Care 2014;59(11):1716-1725. (C) 2014 Daedalus Enterprises]
\end{abstract}

Introduction

Asthma is a chronic disease of the airways with a major impact on global health, with prevalence of 5-10\% worldwide. ${ }^{1}$ The prevalence of asthma among the Jordanian

Drs Basheti and Qunaibi are affiliated with the Department of Clinical Pharmacy and Therapeutics, Applied Science University, Amman, Jordan; Dr Hamadi is affiliated with the Department of Pharmacology and Biomedical Sciences, Petra University, Petra, Jordan; and Dr Reddel is affiliated with the Woolcock Institute of Medical Research, Glebe, New South Wales, Australia. population is increasing and has been estimated to be $\sim 5 \% .^{2}$ Despite well-established management guidelines and effective medications, asthma still remains a poorly controlled condition among many people. One of the reasons

Supplementary material related to this paper is available at http:// www.rcjournal.com.

Dr Basheti presented this research in poster format at the 15th Scientific Congress of the Association of Pharmacy Colleges in the Arab World and 3rd International Conference of the Faculty of Pharmacy-The University 
is poor technique with the use of inhaled medications, ${ }^{3,4}$ including pressurized metered-dose inhalers (MDIs) and dry powder inhalers (DPIs) such as Turbuhaler, Diskus (Accuhaler), and Diskhaler. Poor inhaler technique results in poor asthma control, increased adverse effects, and higher costs. $^{5,6}$ One study of 4,078 patients with asthma treated with inhaled corticosteroid therapy found that $71 \%$ of patients used their MDIs incorrectly, resulting in poor asthma control and increased emergency visits. ${ }^{5}$

The acceptance of DPIs has been driven in large part by their use for the delivery of combination inhaled corticosteroids and long-acting $\beta_{2}$-agonists. ${ }^{7}$ When they were launched, DPI devices were promoted as being easier to use compared with MDIs, because they did not require coordination between actuation and breathing, ${ }^{8}$ and many patients prefer DPIs over other devices9; however, this does not mean that these devices have been used correctly. ${ }^{9}$

In the last decade, DPIs have been found to be used just as poorly as MDIs. The proportions of people with asthma or COPD using inhaler devices incorrectly were similar for MDIs (24\%), Turbuhaler (23\%), and Diskus (24\%). ${ }^{10}$ This suggests the need to investigate further optimization of all device users' technique.

Good asthma management is said to be $10 \%$ medication and $90 \%$ education, ${ }^{11}$ so who is educating asthma patients on correct inhaler technique? Where do healthcare professionals (HCPs) stand with regard to this problem? Incorrect inhaler technique has been reported among community pharmacists, ${ }^{12-15}$ respiratory therapists and physicians, ${ }^{16-18}$ pediatricians, ${ }^{19}$ nurses, ${ }^{20,21}$ emergency medicine house staff, ${ }^{22}$ and hospital-based pharmacists, ${ }^{23}$ with the problem including both MDIs ${ }^{12,19,21}$ and the newer

of Jordan, held October 9-11, 2012, in Amman, Jordan; and at the Al-Zaytoonah University of Jordan and the University of Toledo International Pharmaceutical Conference (ZTIPC 2012), held October 17-19, 2012, in Amman, Jordan.

The workshop costs were sponsored by AstraZeneca Jordan. GlaxoSmithKline provided placebo Diskus, pressurized metered-dose inhalers, and flow meters; AstraZeneca provided placebo Turbuhalers. Dr Reddel has provided independent medical education at symposia funded by AstraZeneca, GlaxoSmithKline, and Novartis; has participated in advisory boards for AstraZeneca, GlaxoSmithKline, Novartis, and Boehringer Ingelheim; has provided consultancy for GlaxoSmithKline; is participating in a joint data monitoring committee for studies funded by AstraZeneca, GlaxoSmithKline, Merck, and Novartis; and has received unconditional grants from AstraZeneca and GlaxoSmithKline for investigator-sponsored research. The other authors have disclosed no conflicts of interest.

Correspondence: Iman A Basheti PhD, Department of Clinical Pharmacy and Therapeutics, Applied Science University, Amman 11931, Jordan. E-mail: dr_iman@asu.edu.jo.

DOI: $10.4187 /$ respcare.02671

\section{QUICK LOOK}

\section{Current knowledge}

Successful asthma management includes appropriate pharmacotherapy and patient education in optimum inhaler technique. Across a range of health-care professionals (HCPs), the ability to demonstrate correct inhaler technique has been shown to be quite variable.

\section{What this paper contributes to our knowledge}

With the exception of specialists, HCPs in Jordan scored poorly in demonstrating the correct use of the dry powder inhalers when compared with pressurized metereddose inhalers. A single educational workshop on inhaler technique significantly improved long-term demonstration of these skills.

DPIs. ${ }^{13,24}$ Hence, a solution to the problem of incorrect inhaler technique by patients must start with HCPs.

The aim of this study was to assess the ability of a range of HCPs in Jordan to demonstrate the correct use of inhaler devices (MDIs and DPIs) before education (baseline) and before and after an educational workshop, ${ }^{25}$ and to assess the long-term effect of this workshop.

\section{Methods}

This study was approved by the ethics committees at Jordan University Hospital (public hospital) and Al-Petra University. HCPs (medical respiratory specialists, general physicians [GPs], pharmacists, pharmacists' assistants, nurses, and respiratory therapists [RTs]) were selected randomly to be approached about the study, using a random number generator and complete HCP lists provided by the relevant professional societies. HCPs were recruited from different hospitals (public and private) and community pharmacies in Amman, Jordan. All HCPs who agreed to participate in this study signed informed consent. They were invited to attend an educational workshop, designed in accordance with a model previously developed and validated by one of the authors (IB). ${ }^{25}$ Inclusion criteria included current practice at a hospital or community pharmacy located within the Amman area, and not being involved in any other clinical study.

\section{Phase 1: HCPs Demographic and Asthma Knowledge Assessments}

After signing consent, participants completed questionnaires regarding their demographic characteristics, their knowledge on asthma devices (Diskus, Turbuhaler, and 
MDI), previous education, previous personal use of any of the devices, confidence in counseling patients on each of the devices, whether they had a specific system aimed at detecting patients with incorrect device technique, and whether they considered such a system is to be important (questionnaire is available upon request from the author); participants also completed an asthma knowledge questionnaire. The asthma knowledge questionnaire comprised 18 true/false questions about asthma and its treatment, exactly as published by Kritikos et $\mathrm{al}^{26}$ with the exception that question 12 (about an Australia-specific incentivized GP program) was omitted; the asthma knowledge questionnaire score is therefore presented as mean score $\pm \mathrm{SD}$ out of 17. All questionnaires were administered in English, as English is the official language of education for all HCPs in Jordan.

\section{Phase 2: Baseline Inhaler Technique Assessment}

Following questionnaire completion, each HCP was asked to demonstrate the use of the Diskus, Turbuhaler, and MDI in random order. Device technique for all HCPs was scored by the same investigator, with reference to a 9-point published checklist for each (Table 1). ${ }^{27,28}$ The researcher assigned one point for each correct step and zero points for incorrect/missed step(s), and added the points to give the participant's inhaler technique score; for each checklist, a score of 9 indicates optimal use.

\section{Phase 3: Workshop with Pre-Training and Post-Training Inhaler Technique Assessment, Questionnaire Completion, and Group Discussion}

All HCPs were invited to attend an educational workshop on asthma management. Two evening workshops were offered at the Ibn Al-haitham Hospital (Amman, Jordan) during June 2009 from 6 to 8 pm. The workshop environment satisfied the requirements for a good learning environment. ${ }^{31}$ The workshop costs were sponsored by AstraZeneca Jordan. GlaxoSmithKline provided placebo Diskus inhalers, placebo MDIs, and flow meters. AstraZeneca provided placebo Turbuhaler inhalers. A summary of the learning techniques, time, and content of each segment of the workshop ${ }^{25}$ is provided online (see the supplementary materials at http://www.rcjournal.com).

After initial inhaler technique assessment, all participants were educated on correct inhaler technique using previously published methods including a physical demonstration. ${ }^{25}$ All participants were then assessed again on their inhaler technique demonstration skills for the 3 devices in random order, by the same researcher as in phase 2 . While other attendees were being assessed on inhaler technique, the remaining participants were involved in a discussion regarding the barriers and solutions to patient ed-
Table 1. Checklists for Assessment of Diskus, Turbuhaler, and MDI Technique in Adults

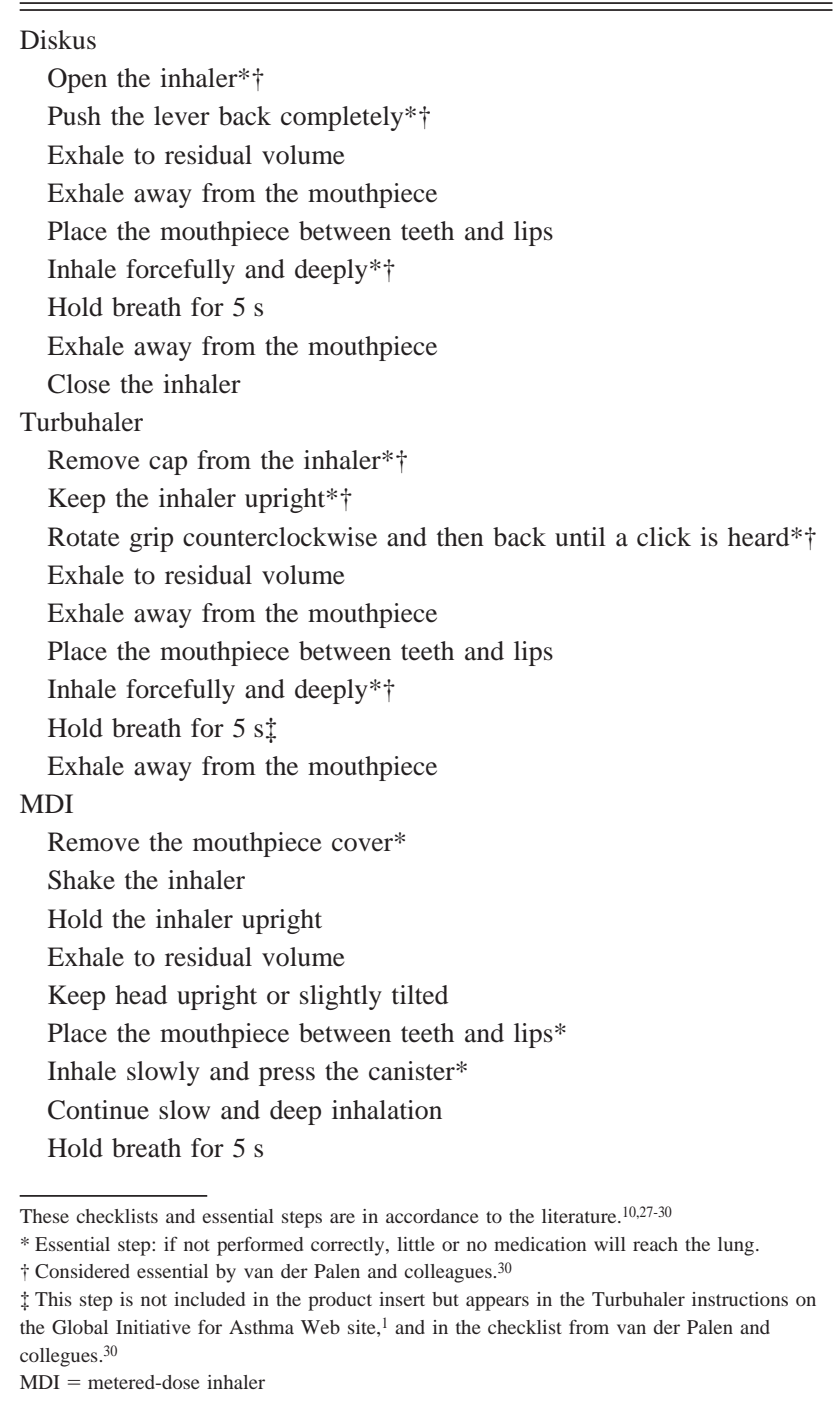

ucation on correct inhaler technique (reported elsewhere). At the end of the workshop, participants were asked to complete a questionnaire about their satisfaction with the workshop (reported elsewhere).

\section{Phase 4: Follow-up Inhaler Technique Assessment and Questionnaire Completion}

All participants who signed informed consent at the beginning of the study were revisited by the same researcher in October 2009, 4 months following the workshop. Participants were asked to complete a questionnaire and then were assessed on their inhaler demonstration skills.

\section{Data Analysis}

Data were analyzed using SPSS 17 software (SPSS, Chicago, Illinois). Inhaler technique data were compared 
at 4 time points: baseline, workshop pre-training, workshop post-training, and 4-month follow-up after the workshop. Comparisons between groups were performed by one-way analysis of variance, and proportional data were analyzed using Pearson chi-square test (or Fisher exact test). To assess whether inhaler technique at the 4-month follow-up assessment was significantly related to attendance at the workshop, and whether this long-term impact of the workshop varied according to the type of $\mathrm{HCP}$ and/or the type of device, one-way between groups analysis of covariance was conducted.

In order to determine predictors of workshop attendance, a backwards logistic regression analysis was performed. The dependent variable was attending the workshop, and independent variables that could plausibly have affected the attendance rate were included, including age, gender, years of experience, asthma knowledge scores, receiving previous experience, profession (specialist, GP, pharmacist, pharmacist assistant, nurse, RT), baseline inhaler technique scores, and baseline confidence about demonstrating inhaler use (not confident, confident, very confident). For all statistical analyses, $P$ values of .05 or less were considered significant. No multiplicity adjustment was made.

\section{Sample Size Calculations}

Sample size calculation was based on previous research results, ${ }^{14}$ which showed an absolute (percentage point) improvement in pharmacists' mean inhaler technique scores of $22.6 \% \pm 18.7 \%$ and $38.4 \% \pm 19.6 \%$ for the Turbuhaler and the Diskus, respectively, after receiving education. With $80 \%$ power, $5 \%$ risk of a type 1 error, and the more conservative of these 2 estimates (for Turbuhaler), it was determined that 22 pharmacists should be recruited. ${ }^{25}$ It was decided to recruit the same number of subjects for all other HCPs (respiratory specialists, GPs, pharmacists' assistants, nurses, and RTs), assuming a maximal 20\% drop out rate, which equaled recruiting a minimum of $160 \mathrm{HCPs}$.

\section{Results}

\section{Study Participants}

A total of $496 \mathrm{HCPs}$ were invited to participate in this study (Fig. 1). Two hundred HCPs (40\%) agreed to participate: 10 respiratory specialists (hereafter referred to as specialists) (5\%), 46 GPs (23\%), 79 pharmacists (39\%), 15 pharmacist assistants (8\%), 40 nurses (20\%), and 10 RTs (5\%). Demographic information is shown in Table 2. Participants were from 4 hospitals ( 2 private and 2 public) and different community pharmacies in Amman, Jordan with a balance between western (higher socioeconomic) and eastern (lower socioeconomic) areas.

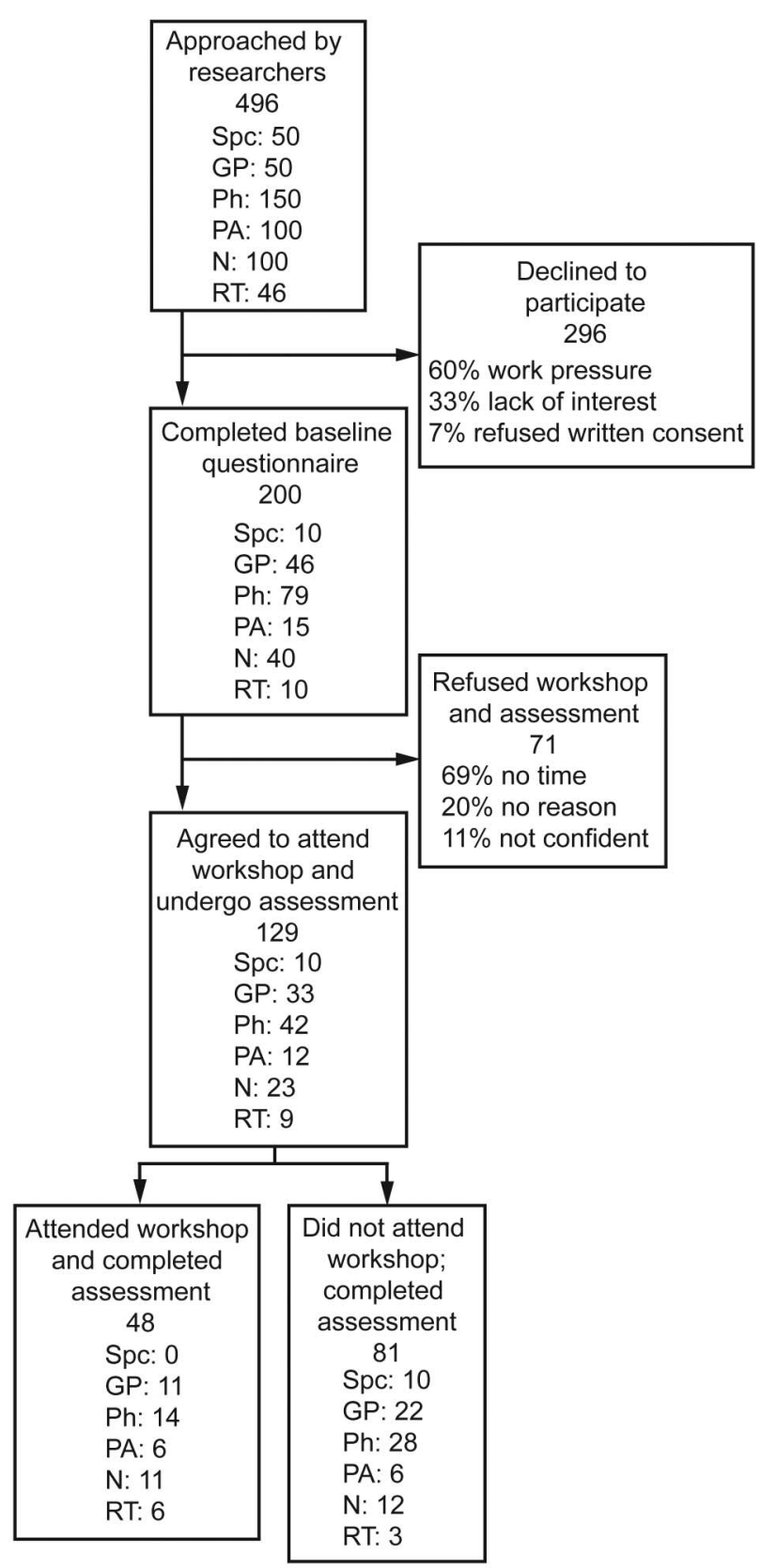

Fig. 1. Flow chart showing disposition and retention throughout recruitment, pre-workshop, workshop, and post-workshop assessment. Spc = specialists; GP = general practitioners; $\mathrm{Ph}=$ pharmacists; $\mathrm{PA}=$ pharmacist assistants; $\mathrm{N}=$ nurses; $\mathrm{RT}=$ respiratory therapists.

\section{Phase 1: Asthma and Inhaler Knowledge}

For asthma knowledge (asthma knowledge questionnaire score out of 17; see Table 2), 26 there was significant variation between HCPs $(P<.001)$, with specialists scoring the highest $(13.80 \pm 0.79)$, and nurses the lowest $(7.95 \pm 2.29)$. 
Inhaler Technique Training and Health-Care Professionals

Table 2. Demographic Information and Information on Asthma Device Use by the Participating HCPs

\begin{tabular}{|c|c|c|c|c|c|c|}
\hline \multirow{2}{*}{ Information } & \multicolumn{6}{|c|}{ Profession $(n=200)$} \\
\hline & Specialist & GP & Pharmacist & PA & Nurse & RT \\
\hline$n$ & 10 & 46 & 79 & 15 & 40 & 10 \\
\hline Gender ( $\%$ male $)$ & 100 & 72 & 37 & 40 & 23 & 80 \\
\hline Age $($ mean $\pm \mathrm{SD})$ & $44.7 \pm 7.5$ & $30.7 \pm 5.6$ & $33.6 \pm 8.4$ & $33.7 \pm 9.5$ & $28.7 \pm 5.7$ & $40.7 \pm 11.0$ \\
\hline Practice years $($ mean $\pm \mathrm{SD})$ & $16.1 \pm 9.4$ & $4.9 \pm 5.2$ & $11.4 \pm 8.2$ & $12.2 \pm 8.9$ & $7.6 \pm 4.9$ & $15.7 \pm 8.9$ \\
\hline Place of work $(n)$ & $\begin{array}{l}\mathrm{H}(6) \\
\mathrm{PC}(4)\end{array}$ & $\mathrm{H}(46)$ & $\begin{array}{l}\mathrm{H}(33) \\
\mathrm{CP}(46)\end{array}$ & $\mathrm{H}(15)$ & $\mathrm{H}(40)$ & $\mathrm{H}(10)$ \\
\hline Asthma knowledge score $($ mean $\pm \mathrm{SD}) *$ & $13.8 \pm 0.8$ & $10.4 \pm 2.2$ & $9.4 \pm 2.5$ & $9.5 \pm 2.4$ & $8.0 \pm 2.3$ & $10.4 \pm 2.0$ \\
\hline \multicolumn{7}{|l|}{ Previous education (\% yes) } \\
\hline Diskus & 100 & 39 & 53 & 67 & 20 & 100 \\
\hline Turbuhaler & 100 & 41 & 52 & 47 & 35 & 100 \\
\hline MDI & 90 & 65 & 53 & 60 & 43 & 100 \\
\hline \multicolumn{7}{|l|}{$\begin{array}{l}\text { Time since last education on inhaler use, } \\
\qquad \mathrm{y}(\text { mean } \pm \mathrm{SD}) \dagger\end{array}$} \\
\hline Diskus & $8.3 \pm 3.4$ & $1.9 \pm 1.4$ & $4.7 \pm 5.3$ & $4.5 \pm 4.2$ & $2.2 \pm 1.3$ & $3.6 \pm 2.7$ \\
\hline Turbuhaler & $8.6 \pm 3.4$ & $3.4 \pm 2.5$ & $5.0 \pm 5.0$ & $4.6 \pm 4.9$ & $2.1 \pm 1.1$ & $7.0 \pm 5.9$ \\
\hline MDI & $15.1 \pm 8.4$ & $3.5 \pm 3.8$ & $6.6 \pm 6.6$ & $6.3 \pm 6.6$ & $2.1 \pm 1.3$ & $10.9 \pm 10.5$ \\
\hline Personal use of any inhaler, $n$ (\% yes) & $6(60)$ & $12(26)$ & $17(22)$ & $4(27)$ & $5(13)$ & $4(40)$ \\
\hline \multicolumn{7}{|l|}{$\begin{array}{l}\text { Confident in proper inhaler counseling } \\
(\% \text { yes; VC:C:NC })\end{array}$} \\
\hline Diskus & 90:10:0 & $13: 30: 57$ & $24: 26: 50$ & $20: 47: 33$ & $12: 10: 78$ & 50:50:0 \\
\hline Turbuhaler & 90:10:0 & $11: 33: 56$ & $21: 32: 47$ & $20: 33: 47$ & $15: 22: 63$ & 50:50:0 \\
\hline MDI & 90:10:0 & $24: 41: 35$ & $23: 32: 45$ & $27: 40: 33$ & $20: 27: 53$ & $60: 40: 0$ \\
\hline $\begin{array}{l}\text { Do you have a specific system aimed at detecting patients } \\
\text { with incorrect device technique? \% yes }(n)\end{array}$ & $100(10)$ & $65(30)$ & $21(17)$ & $27(4)$ & $40(16)$ & $70(7)$ \\
\hline $\begin{array}{l}\text { Is it useful to have a reviewing system for patients' } \\
\text { inhaler assessment? \% yes }(n)\end{array}$ & $100(10)$ & $94(43)$ & $85(67)$ & $73(11)$ & $75(30)$ & $100(10)$ \\
\hline$\%(n)$ agreeing to assessment $\neq$ & $100(10)$ & $39(18)$ & $53(42) \S$ & $67(10)$ & $20(8)$ & $100(10)$ \\
\hline \multicolumn{7}{|l|}{ Baseline technique scores (mean $\pm \mathrm{SD}$ ) } \\
\hline Diskus & $6.3 \pm 1.7$ & $4.8 \pm 0.5$ & $5.2 \pm 0.9$ & $5.1 \pm 0.9$ & $4.9 \pm 0.4$ & $4.9 \pm 0.3$ \\
\hline Turbuhaler & $6.4 \pm 1.7$ & $5.0 \pm 0.8$ & $5.2 \pm 1.1$ & $5.6 \pm 0.8$ & $5.0 \pm 0.4$ & $4.9 \pm 0.3$ \\
\hline MDI & $8.7 \pm 0.7$ & $7.9 \pm 0.9$ & $7.7 \pm 0.9$ & $8.2 \pm 1.2$ & $7.2 \pm 1.0$ & $8.4 \pm 0.7$ \\
\hline $\begin{array}{l}\text { Inhaler technique scores are out of } 9 \text { for all devices. } \\
\text { * Asthma Knowledge Questionnaire score (out of } 17)^{26} \\
\dagger \text { This indicates the last time that health-care professionals }(\mathrm{HCPs}) \text { received ed } \\
\text { ¥ Proportion of HCPs per group who agreed to demonstrate their inhaler techn } \\
\text { \& Inhaler technique scores for these } 42 \text { pharmacists were previously reported. } \\
\text { GP }=\text { general practitioner } \\
\mathrm{PA}=\text { pharmacist assistant } \\
\mathrm{RT}=\text { respiratory therapist } \\
\mathrm{MDI}=\text { metered dose inhaler } \\
\mathrm{VC}=\text { very confident } \\
\mathrm{C}=\text { confident } \\
\mathrm{NC}=\text { not confident } \\
\mathrm{H}=\text { hospital } \\
\mathrm{PC}=\text { private clinic } \\
\mathrm{CP}=\text { community pharmacy }\end{array}$ & $\begin{array}{l}\text { ation specific for } \\
\text { le skills. }\end{array}$ & relevant inhalers. & & & & \\
\hline
\end{tabular}

Only about half of HCPs had received previous education on inhaler technique, with $49 \%, 50.5 \%$, and $58.5 \%$ reporting that they had received education on Diskus, Turbuhaler, and MDI, respectively. Significantly more specialists and RTs had received previous education on the devices compared with other HCPS $(P=.004)$ (see Table 2).
The most common source of education on device technique was hospital practice ( $31 \%$ of participants), followed by self-taught (19\%), university education (11\%), pharmaceutical manufacturer representatives $(7 \%)$, and continuing education programs (5\%); $27 \%$ reported a combination of these sources. A significant difference in the source of education between HCPs was found $(P<.001)$, with the 
Inhaler Technique Training and Health-Care Professionals

Table 3. Inhaler Technique Score Before and After Training for All HCPs Who Attended the Workshop

\begin{tabular}{|c|c|c|c|c|c|c|c|c|c|}
\hline \multirow{2}{*}{$\begin{array}{l}\text { Profession } \\
(n=48)\end{array}$} & \multicolumn{3}{|c|}{ Diskus } & \multicolumn{3}{|c|}{ Turbuhaler } & \multicolumn{3}{|c|}{ MDI } \\
\hline & Pre & Post & $P^{*}$ & Pre & Post & $P^{*}$ & Pre & Post & $P^{*}$ \\
\hline Specialist $(n=0)$ & ND & ND & ND & ND & ND & ND & ND & ND & ND \\
\hline $\mathrm{GP}(n=11)$ & $8.55 \pm 0.52$ & $8.90 \pm 0.30$ & .100 & $7.09 \pm 1.04$ & $8.55 \pm 0.69$ & .001 & $5.18 \pm 0.60$ & $8.91 \pm 0.30$ & $<.001$ \\
\hline Pharmacist $(n=14)$ & $2.00 \pm 1.04$ & $8.75 \pm 0.45$ & $<.001$ & $4.29 \pm 2.16$ & $8.79 \pm 0.43$ & $<.001$ & $3.50 \pm 0.94$ & $8.93 \pm 0.27$ & $<.001$ \\
\hline PA $(n=6)$ & $4.67 \pm 0.52$ & $9.00 \pm 0.00$ & .001 & $6.33 \pm 1.37$ & $8.67 \pm 0.52$ & .003 & $6.33 \pm 0.52$ & $8.50 \pm 0.55$ & .003 \\
\hline Nurse $(n=11)$ & $4.00 \pm 0.78$ & $8.82 \pm 0.60$ & $<.001$ & $4.09 \pm 0.83$ & $8.64 \pm 0.67$ & $<.001$ & $6.18 \pm 1.17$ & $8.73 \pm 0.65$ & .001 \\
\hline $\mathrm{RT}(n=6)$ & $2.83 \pm 1.17$ & $8.83 \pm 0.41$ & $<.001$ & $2.83 \pm 1.17$ & $8.33 \pm 1.21$ & $<.001$ & $2.83 \pm 1.17$ & $8.50 \pm 0.84$ & .001 \\
\hline $\begin{array}{l}\text { * Paired sample } t \text { test for co } \\
\text { HCP }=\text { health-care professic } \\
\text { Pre }=\text { before training } \\
\text { Post }=\text { training } \\
\text { MDI = metered-dose inhale } \\
\text { ND }=\text { no data } \\
\text { GP }=\text { general practitioner } \\
\text { PA }=\text { pharmacist assistant } \\
\text { RT }=\text { respiratory therapist }\end{array}$ & son of pre-tra & post-training & que so & ler technique & $($ mean $\pm \mathrm{SD})$ & of $9 \mathrm{f}$ & & & \\
\hline
\end{tabular}

majority of physicians self-taught or educated by manufacturers' representatives, whereas inhaler education was mainly received at university for pharmacists, and in hospitals for RTs and nurses.

Few HCPs had received any recent training on inhaler devices, with fewer than $7 \%$ reporting education in the previous $1 \mathrm{y}$, and only $29 \%$ in the previous $5 \mathrm{y}$. A significant difference between HCPs was found with regard to time since last education $(P<.005)$, with nurses and GPs reporting more recent education on inhaler devices than other HCPs (see Table 2).

Overall, 48 HCPs (24\%) had personally used one or more devices for asthma, COPD, or seasonal allergy (see Table 2), particularly specialists and RTs $(P=.037)$.

High confidence in counseling patients on correct inhaler technique was expressed by $32 \%$ of HCPs for Diskus, 34\% for Turbuhaler, and 41\% for MDI. For Diskus, all specialists and RTs stated that they felt highly confident or confident, whereas 33-78\% of the other HCPs felt they lacked confidence; similar results were obtained for Turbuhaler and MDI (see Table 2).

Fifty-four percent of HCPs specified that they already followed a system for assessing, educating, and reviewing their asthmatic patients on correct inhaler technique, with specialists most likely to report that they already followed such a system, compared with $65 \%$ of GPs and $21 \%$ of pharmacists (see Table 2). However, $88 \%$ of HCPs agreed that there is a need for such a system (see Table 2).

\section{Phase 2: Baseline Inhaler Technique Assessment}

Sixty-five percent of participants $(n=129)$ agreed to demonstrate their inhaler technique; the proportion who agreed ranged from $100 \%$ for specialists and RTs to $67 \%$ for pharmacists' assistants and $20 \%$ for nurses (see Table 2).
Overall, significantly better inhaler technique was observed with MDIs than the newer DPIs (Diskus and Turbuhaler) across all devices (see Table 2), but only $22.5 \%$ of HCPs demonstrated $100 \%$ correct technique on all 3 devices.

\section{Phase 3: Workshop (Pre-Training and Post-Training Inhaler Technique Assessment)}

All 129 HCPs who had demonstrated their inhaler technique agreed to attend the workshop (the workshop was offered only to those who agreed to show their technique), but only 48 HCPs (37\%) actually attended (see Fig. 1). None of the specialists attended the workshop. Logistic regression modeling, with baseline inhaler scores, confidence levels, and profession included in the model, identified profession to be the only variable significantly associated with workshop attendance $(P \leq .001$, $\left.\mathrm{R}^{2}=0.10\right)$.

Inhaler technique scores (mean $\pm \mathrm{SD}$ ) before and after training are presented in Table 3 . In the pre-training assessment, GPs demonstrated significantly better inhaler technique devices than pharmacists and RTs (Diskus, $P \leq .001$; Turbuhaler, $P \leq .002$; MDI, $P \leq .001)$. They also performed significantly better than nurses for Diskus and Turbuhaler $(P<.001$ for both devices for all). GPs performed better than pharmacists' assistants only for the Diskus $(P<.001)$.

Inhaler technique was significantly better on post-training assessment for all devices (Fig. 2). All groups improved significantly in their inhaler technique scores after education (see Table 3) except for GPs with Diskus technique, which was already excellent before training. 

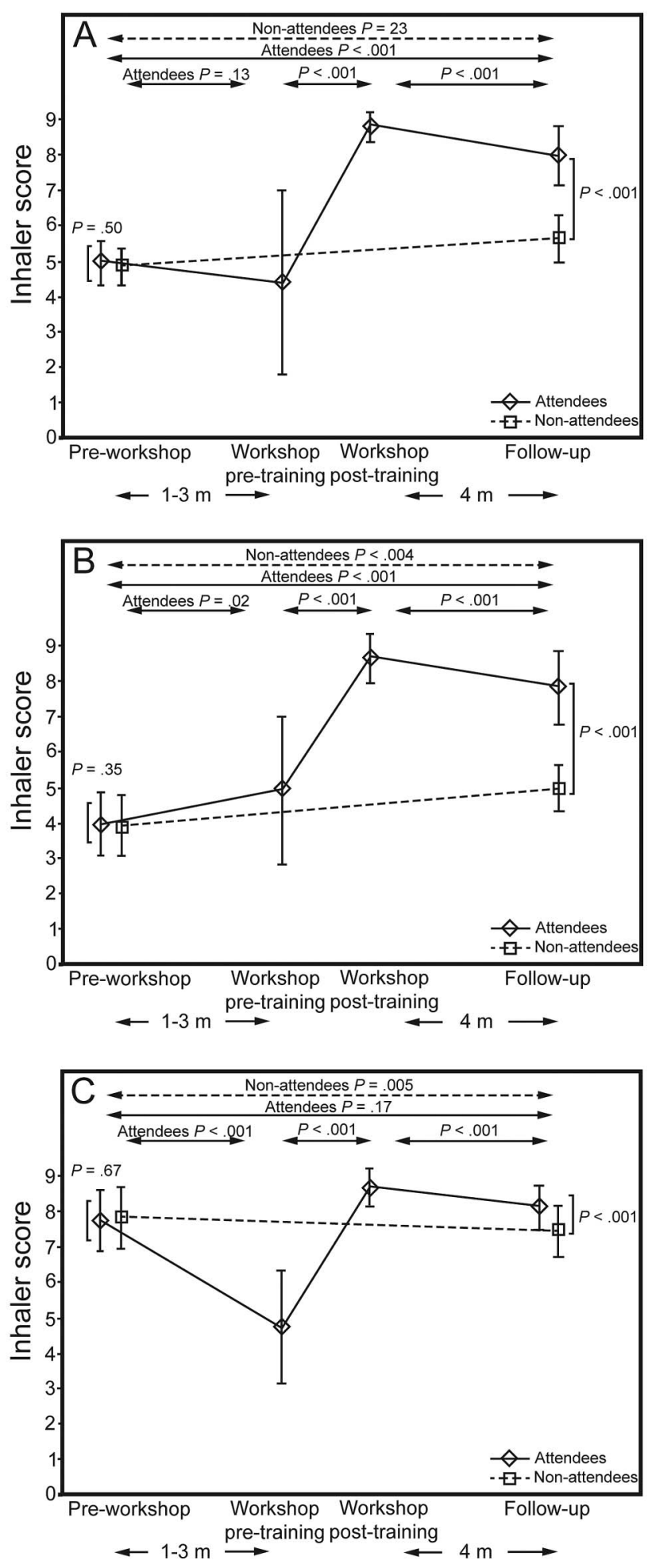

Fig. 2. Inhaler technique scores (mean \pm SD, 95\% Cl) for all health care practitioners (workshop attendees $[n=48]$ and nonattendees $[n=81])$ at all stages of study. Inhalers used are Diskus (A), Turbuhaler (B), and metered-dose inhaler (C).

\section{Phase 4: Follow-up Inhaler Technique Assessment}

Four months following the workshop, all 129 HCPs who had provided baseline inhaler technique were re-assessed. Participants who had attended the workshop $(n=48)$ demonstrated significantly better inhaler technique than participants who did not attend the workshop $(n=81)$ (Fig. 3), with mean scores across all 3 inhaler types being 7.64 versus 5.99 , respectively $(P<.001)$.

With the baseline scores (after first questionnaire completion) as a covariate, there was a significant difference between the professions in inhaler technique scores at 4 months $(P=.01)$. Post hoc analysis showed that nurses' scores at 4 months were significantly higher than those of pharmacists $(P=.02)$ and pharmacists' assistants $(P=.01)$, perhaps relating to greater opportunity to train patients in correct inhaler technique as part of their day-to-day work.

Type of inhaler significantly affected the scores at 4 months $(P<.001)$, with MDI scores significantly higher than both Diskus $(P<.001)$ and Turbuhaler $(P<.001)$ scores. No significant differences were found between the DPIs (Diskus and Turbuhaler) $(P=.72)$.

\section{Discussion}

This is the first study to show the long-term positive impact of a feasible educational workshop on inhaler technique education, targeting a range of HCPs engaged in patient asthma education. We previously reported the positive impact of a similar workshop designed for pharmacists, but the effect of the workshop itself on their inhaler technique skills was not able to be assessed due to the participants' involvement in a 6-month follow-up study on inhaler technique education for patients with asthma. ${ }^{25}$ However, in this study we have shown that such a workshop can, on its own, optimize inhaler technique for HCPs, and these skills were maintained over a period of 4 months compared to those demonstrated by untrained colleagues.

Previous reports on inhaler technique education for HCPs have shown that correct demonstration skills can be achieved in a single teaching session ${ }^{3,23,32}$; however, these skills were not maintained over a period as short as 2-3 months. ${ }^{23,32}$

In Jordan, asthma prevalence is not low, with $4.1 \%$ of the adult population diagnosed, and $8.3 \%$ reporting wheeze. Among children, the rates are also high and increasing. ${ }^{33}$ Few patients with asthma use their inhaler devices correctly, with up to $75 \%, 43 \%$, and $7 \%$ of patients incorrectly using MDI, Turbuhaler, and Diskus devices, respectively. ${ }^{34}$ Basheti et al reported that, despite differences in Jordan's and Australia's health systems, pharmacists and patients from both countries had difficulty with using both Turbuhaler and Diskus devices correctly. ${ }^{4}$ Hence, strict 


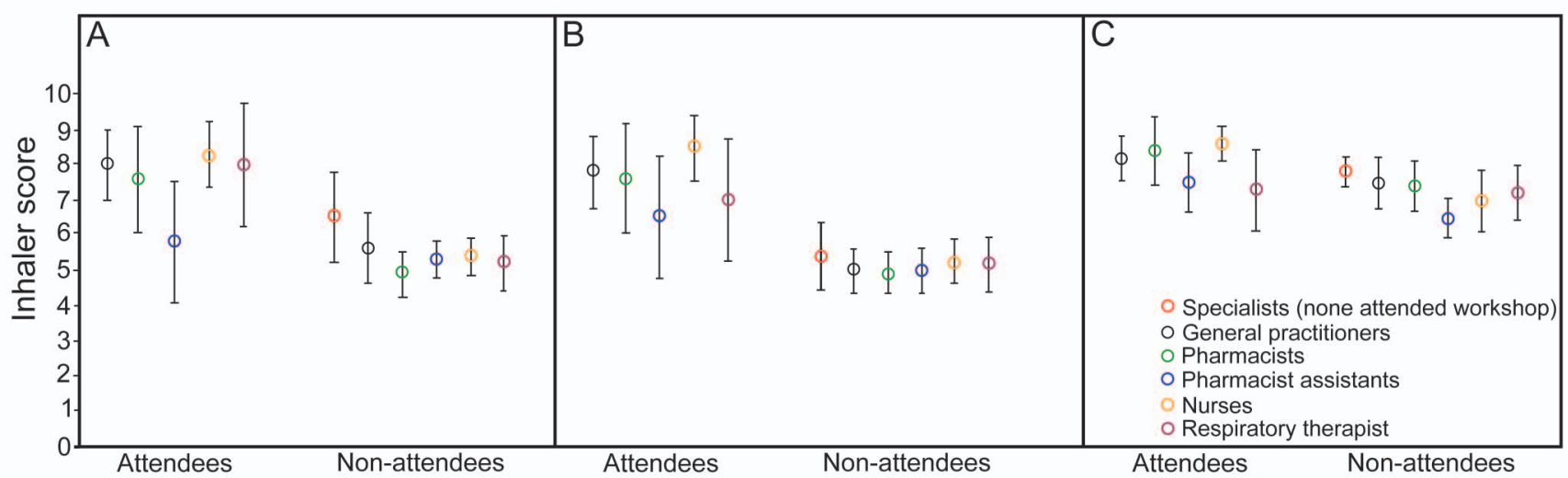

Fig. 3. Inhaler technique scores (mean \pm SD, 95\% Cl) for all health care practitioners (workshop attendees $[n=48]$ and non-attendees $[n=81]) 4$ months after workshop. Inhalers used are Diskus (A), Turbuhaler (B), and metered-dose inhaler (C).

measures to improve inhaler technique are definitely needed.

It is vital to investigate the factors contributing to poor inhaler technique among asthmatics in Jordan. Hospital pharmacies in Jordan have dispensing windows, creating a physical barrier between the pharmacist and the patient. Medications are placed in front of the windows for the patient to pick up, with no clear system of patient education and counseling. Community pharmacies present further barriers. Although they are the most accessible primary healthcare facilities in the country, patients rarely consider receiving education from the pharmacist. ${ }^{35}$ This is a lost opportunity, considering the high number of pharmacies $(2,800)$ ready to serve a population of $6,388,000$. Barriers vary, from the pharmacist sometimes being absent from the pharmacy, to lack of knowledge among pharmacists and their assistants, to patients' uncertainty regarding the role of the pharmacist. ${ }^{36}$

As expected, ${ }^{26}$ specialists had better inhaler technique and higher confidence levels in demonstrating technique at baseline than other HCPs. This could be due to their experience, more specific education, and the fact that they deal more directly with the management of asthmatic patients. All of the specialists reported that they have a system to identify patients with poor inhaler technique and were already engaged in inhaler technique education. This could have enhanced their inhaler technique demonstration skills. In addition, 6 of 10 specialists reported personal use of asthma devices, which again could have boosted their baseline inhaler technique level or increased their willingness to participate.

Differences were seen in technique with the 3 devices. At baseline, HCPs performed better in demonstrating technique with MDIs than with the Diskus and Turbuhaler. This is not surprising, since MDIs were introduced into the Jordanian market about 5 decades ago (1970), compared with a single decade for the DPIs (2002). Workshop at- tendees demonstrated significantly better inhaler technique at follow-up for the Diskus and Turbuhaler. Nonattendees also improved significantly in demonstrating the Turbuhaler technique at follow-up, although significantly less than the attendees. It is possible that nonattendees received additional training from other sources, eg, manufacturer representatives, during the study period.

Many previous studies have used checklists to assess inhaler technique, ${ }^{10,17,29,37}$ but a large number of different checklists exist, and they often differ substantially. Basheti et al recently reviewed published checklists for Diskus and Turbuhaler, ${ }^{27}$ discussing the rationale and/or evidence for inclusion or exclusion of specific steps, and providing recommendations about standardized checklists; the 9-point checklists used for Diskus and Turbuhaler in the present study corresponded exactly to these recommendations. For MDIs, we used a published 8-point checklist from intervention studies by ourselves and others, ${ }^{28,30}$ and added an item for removal of the inhaler cap to make a 9-point checklist for consistency, and also because this step is essential for delivery of any medication.

Planning of the HCP workshop followed principles established in patient education on inhaler technique. Written information such as medication inserts is not enough, and may convey limited and incomplete information. ${ }^{38,39}$ In addition, the acquisition of knowledge alone does not necessarily translate into effective self-management behaviors $^{40}$; physical demonstration of technique with follow-up assessment and education is essential. ${ }^{3}$ Hence, we integrated hands-on education for HCPs into the workshop following the "train the trainer" approach; this is essential for HCPs to develop their own skills, so they can in turn educate patients to insure effective self-management behaviors. ${ }^{41}$

Recruitment into clinical studies is one of the most challenging phases of $\mathrm{HCP}$ research. ${ }^{42}$ In this study, only $40 \%$ of HCPs who were approached agreed to participate, and 
only $10 \%$ ultimately attended the workshop. Many strategies were followed to optimize the number of attendants, from informative invitation letters, to feasible free of charge workshop and reminder telephone calls. Pharmacists responded best to the recruitment phase (40\% of HCPs), perhaps because they were being approached by a pharmacist.

Knowing the current sources of inhaler device education for HCPs is necessary to target and improve these sources. Significant differences were reported between HCPs regarding their source of inhaler education. For example, manufacturer representatives played the major role for specialists; for RTs, nurses, and GPs, hospital education; for the pharmacists, university education; and for pharmacists' assistants, a combination of these sources. Hence, to improve skills of all relevant HCPs, we need to upgrade the skills of manufacturer representatives, universities, and hospital staff. In addition, the present results suggest that providing educational workshops is essential for maintaining optimal skills. Participant feedback in this study suggests that, without making continuing educational workshops mandatory, attendance by HCPs will remain poor even if the workshops are delivered free of charge.

Results of this study may be limited by the small proportion of HCPs who agreed to participate, introducing nonresponse bias. Out of the recruited HCPs, only 48 attended the workshop, which could have affected the study findings. Data from the questionnaires were dependent on self-reporting by participants; thus, inaccuracies may be inherent due to social desirability bias and the potential for misinterpreting questions. However, this was minimized by establishing face and content validity, by piloting the questionnaire before distribution and making it anonymous, and by using a standardized checklist for assessing inhaler technique. The results of this study apply only to the context in Jordan, and cannot necessarily be generalized to other countries, which may have different training programs for health professionals.

\section{Conclusions}

Poor asthma knowledge and inhaler technique skills among HCPs remain a problem in Jordan, reducing the effectiveness of asthma treatment received by patients. An educational intervention for a range of HCPs, involving a 2-h workshop based on adult learning principles, has been shown to be effective in enhancing their skills and confidence in both short term and long term. Although this study has provided valuable information about asthma and inhaler technique education from the HCPs' perspective, exploring patients' perspectives on the role of the HCPs in contributing to patient care and asthma management in Jordan would help in developing clear strategies to improve the provision of asthma education in the region.

\section{ACKNOWLEDGMENTS}

We would like to acknowledge the researchers Noor Al-Saraj and Anas I Natsheh for their help in conducting this research and Dr Mamoon Zuhluf MD (Consultant, Critical Care and Pulmonary, Islamic Hospital, Amman, Jordan) for his help in conducting the workshops.

\section{REFERENCES}

1. Global Initiative for Asthma (GINA). Global Strategy for Asthma Management and Prevention: revised workshop report (2012). Chapters 1-5. http://wwwginasthmaorg. Accessed May 2012.

2. Abuekteish F, Alwash R, Hassan M, Daoud AS. Prevalence of asthma and wheeze in primary school children in northern Jordan. Ann Trop Paediatr 1996;16(3):227-231.

3. Basheti IA, Armour CL, Bosnic-Anticevich SZ, Reddel HK. Evaluation of a novel educational strategy, including inhaler-based reminder labels, to improve asthma inhaler technique. Patient Educ Couns 2008;72(1):26-33.

4. Basheti IA, Qunaibi E, Bosnic-Anticevich SZ, Armour CL, Khater S, Omar M, Reddel HK. User error with Diskus and Turbuhaler by asthma patients and pharmacists in Jordan and Australia. Respir Care 2011;56(12):1916-1923.

5. Giraud V, Roche N. Misuse of corticosteroid metered-dose inhaler is associated with decreased asthma stability. Eur Respir J 2002;19(2): 246-251.

6. King D, Earnshaw SM, Delaney JC. Pressurised aerosol inhalers: the cost of misuse. Br J Clin Pract 1991;45(1):48-49.

7. Atkins PJ. Dry powder inhalers: an overview. Respir Care 2005; 50(10):1304-1312.

8. Crompton GK. The adult patient's difficulties with inhalers. Lung 1990;168 Suppl:658-662.

9. Lenney J, Innes JA, Crompton GK. Inappropriate inhaler use: assessment of use and patient preference of seven inhalation devices. Respir Med 2000;94(5):496-500.

10. Melani AS, Zanchetta D, Barbato N, Sestini P, Cinti C, Canessa PA, et al. Inhalation technique and variables associated with misuse of conventional metered-dose inhalers and newer dry powder inhalers in experienced adults. Ann Allergy Asthma Immunol 2004;93(5): 439-446.

11. Fink JB, Rubin BK. Problems with inhaler use: a call for improved clinician and patient education. Respir Care 2005;50(10):1360-1374.

12. Mickle TR, Self TH, Farr GE, Bess DT, Tsiu SJ, Caldwell FL. Evaluation of pharmacists' practice in patient education when dispensing a metered-dose inhaler. Ann Pharmacother 1990;24(10):927930.

13. Kesten S, Zive K, Chapman KR. Pharmacist knowledge and ability to use inhaled medication delivery systems. Chest 1993;104(6):17371742.

14. Cain WT, Cable G, Oppenheimer JJ. The ability of the community pharmacist to learn the proper actuation techniques of inhaler devices. J Allergy Clin Immunol 2001;108(6):918-920.

15. Khan T, Azhar S. A study investigating the community pharmacist knowledge about the appropriate use of inhaler, Eastern Region Al Ahsa, Saudi Arabia. Saudi Pharm J 2013;21:153-157.

16. Kelling JS, Strohl KP, Smith RL, Altose MD. Physician knowledge in the use of canister nebulizers. Chest 1983;83(4):612-614.

17. Hanania NA, Wittman R, Kesten S, Chapman KR. Medical personnel's knowledge of and ability to use inhaling devices: metered-dose inhalers, spacing chambers, and breath-actuated dry powder inhalers. Chest 1994;105(1):111-116.

18. Tsang KW, Lam WK, Ip M, Kou M, Yam L, Lam B, et al. Inability of physicians to use metered-dose inhalers. J Asthma 1997;34(6): 493-498. 


\section{Inhaler Technique Training and Health-Care Professionals}

19. Amirav I, Goren A, Pawlowski NA. What do pediatricians in training know about the correct use of inhalers and spacer devices? J Allergy Clin Immunol 1994;94(4):669-675.

20. Plaza V, Sanchis J. Medical personnel and patient skill in the use of metered dose inhalers: a multicentric study. CESEA Group. Respiration 1998;65(3):195-198

21. Taylor D, Tunstell P. Metered dose inhalers: system for assessing technique in patients and health professionals. Pharm J 1991;246: 626-627.

22. Jones JS, Holstege CP, Riekse R, White L, Bergquist T. Metereddose inhalers: do emergency health care providers know what to teach? Ann Emerg Med 1995;26(3):308-311.

23. Jackevicius CA, Chapman KR. Inhaler education for hospital-based pharmacists: how much is required? Can Respir J 1999;6(3):237244.

24. Chopra N, Oprescu N, Fask A, Oppenheimer J. Does introduction of new "easy to use" inhalational devices improve medical personnel's knowledge of their proper use? Ann Allergy Asthma Immunol 2002; 88(4):395-400.

25. Basheti IA, Armour CL, Reddel HK, Bosnic-Anticevich SZ. Longterm maintenance of pharmacists' inhaler technique demonstration skills. Am J Pharm Educ 2009;73(2):32.

26. Kritikos V, Saini B, Bosnic-Anticevich SZ, Krass I, Shah S, Taylor $\mathrm{S}$, Armour C. Innovative asthma health promotion by rural community pharmacists: a feasibility study. Health Promot J Austr 2005; 16(1):69-73

27. Basheti IA, Bosnic-Anticevich SZ, Armour CL, Reddel HK. Checklists for powder inhaler technique: a review and recommendations. Respir Care 2014;59(7):1140-1154.

28. Bosnic-Anticevich SZ, Sinha H, So S, Reddel HK. Metered-dose inhaler technique: the effect of two educational interventions delivered in community pharmacy over time. J Asthma 2010;47(3):251256

29. Basheti IA, Reddel HK, Armour CL, Bosnic-Anticevich SZ. Counseling about Turbuhaler technique: needs assessment and effective strategies for community pharmacists. Respir Care 2005;50(5):617623.

30. van der Palen J, Klein JJ, Schildkamp AM. Comparison of a new multidose powder inhaler (Diskus/Accuhaler) and the Turbuhaler regarding preference and ease of use. J Asthma 1998;35(2):147 152

31. Caffarella RS. Planning programs for adult learners. A practical guide for educators, trainers and staff developers. 2nd ed. San Francisco, CA: Jossey-Bass Publications;2002:176-351.

32. Resnick DJ, Gold RL, Lee-Wong M, Feldman BR, Ramakrishnan R, Davis WJ. Physicians' metered dose inhaler technique after a single teaching session. Ann Allergy Asthma Immunol 1996;76(2):145-148.

33. El-Sharif N, Abdeen Z, Qasrawi R, Moens G, Nemery B. Asthma prevalence in children living in villages, cities and refugee camps in Palestine. Eur Respir J 2002;19(6):1026-1034.

34. Khassawneh BY, Al-Ali MK, Alzoubi KH, Batarseh MZ, Al-Safi SA, Sharara AM, Alnasr HM. Handling of inhaler devices in actual pulmonary practice: metered-dose inhaler versus dry powder inhalers. Respir Care 2008;53(3):324-328.

35. Al-Wazaify M, Albsoul-Younes A. Pharmacy in Jordan. Am J Health Syst Pharm 2005;62(23):2548-2551.

36. Qunaibi E, Basheti I, Bulatova N, Shanah A, Hamadi S, Abu-Gharbieh E. Effect of divergence in patients' socioeconomic backgrounds on their perspective of the role of the community pharmacist. Trop J Pharm Res 2013;12(2):247-253.

37. Basheti IA, Reddel HK, Armour CL, Bosnic-Anticevich SZ. Improved asthma outcomes with a simple inhaler technique intervention by community pharmacists. J Allergy Clin Immunol 2007;119(6): 1537-1538.

38. Serra-Batlles J, Plaza V, Badiola C, Morejón E; Inhalation Devices Study Group. Patient perception and acceptability of multidose dry powder inhalers: a randomized crossover comparison of Diskus/Accuhaler with Turbuhaler. J Aerosol Med 2002;15(1):59-64.

39. Sawalha A, Sweileh W, Zyoud S, Jabi S. Comparative analysis of patient package inserts of local and imported anti-infective agents in Palestine. Libyan J Med 2008;3(4):181-185.

40. Gibson PG, Ram FS, Powell H. Asthma education. Respir Med 2003;97(9):1036-1044.

41. Hasan S. Continuing education needs assessment of pharmacists in the United Arab Emirates. Pharm World Sci 2009;31(6):670-676.

42. Wilcock M. The community pharmacist, the patient and their inhaler device: time to work together? Pharm Pract 2002;12(9):356362. 